\title{
O FUNDO PARA A CONVERGÊNCIA ESTRUTURAL DO MERCOSUL (FOCEM): UM DEBATE SOBRE ASSIMETRIAS E INTEGRAÇÃO REGIONAL
}

\author{
DAYANA APARECIDA MARQUES DE OLIVEIRA CRUZ* \\ Universidade Federal de São Carlos
}

Resumo: As assimetrias e descompassos econômicos do Mercado Comum do Sul (MERCOSUL) trouxeram à tona a necessidade de compensar os ganhos econômicos para os membros menores do bloco e impulsionar o incremento técnico nas redes de infraestruturas (transportes e energia). Como resultado das discussões sobre o tema, foi criado o Fundo para a Convergência Estrutural do MERCOSUL (FOCEM), a fim de garantir o aprofundamento da integração regional no bloco. Após quinze anos de sua criação, alguns aspectos necessitam ser debatidos, sobretudo em relação aos critérios territoriais para o financiamento dos projetos e sua complexidade regional.

Palavras-chave: Integração regional; Assimetrias; MERCOSUL; FOCEM; Projetos.

\section{MERCOSUR STRUCTURAL CONVERGENCE FUND (FOCEM): A DEBATE ON ASYMMETRIES AND REGIONAL INTEGRATION}

Abstract: The economic asymmetries and mismatches of the Southern Common Market (MERCOSUR) has brought the need to compensate the economic gains for the smaller members of the bloc and boost the technical increase in infrastructure networks (transport and energy). As a result of the discussions on the subject, the MERCOSUR Structural Convergence Fund (FOCEM) was created to ensure a deepening of regional integration in the bloc. Fifteen years after its creation, some aspects need to be debated, especially in relation to the territorial criteria for the financing of the projects and their regional complexity.

Keywords: Regional integration; Asymmetries; MERCOSUR; FOCEM; Projects.

\section{FUNDO DE CONVERGÊNCIA ESTRUTURAL DO MERCOSUL (FOCEM): UM DEBATE SOBRE ASSIMETRIAS E INTEGRAÇÃO REGIONAL}

Resumen: Las asimetrías y los desajustes económicos del Mercado Común del Sur (MERCOSUR) pusieron de manifiesto la necesidad de compensar las ganancias económicas para los miembros más pequeños del bloque e impulsar el aumento técnico de las redes de infraestructura (transporte y energía). Como resultado de las discusiones sobre el tema, se creó el Fondo para la Convergencia Estructural del MERCOSUR (FOCEM) para garantizar la profundización de la integración regional en el bloque. Quince años después de su creación, es necesario debatir algunos aspectos, especialmente en relación con los criterios territoriales para financiar los proyectos y su complejidad regional.

Palabras-clave: Integración regional; Asimetrías; MERCOSUR; FOCEM; Proyectos. 
Introdução

Embora o MERCOSUL tenha sido criado com a assinatura do Tratado de Assunção em 1991, seus antecedentes remontam à década de 1970 com a aproximação de Brasil e Argentina através do Tratado Tripartite Itaipu-Corpus. A partir daí os países iniciaram um novo capítulo no contexto regional, caracterizado pela aproximação e cooperação, encerrando a fase de disputa geopolítica pela Bacia do Prata (OLIVEIRA, 1998, p.13).

No início de 1990, Uruguai e Paraguai que antes eram alvo da disputa geopolítica e econômica entre Brasil e Argentina na busca pela liderança regional (MELLO, 1987 , p. 176), viram na cooperação destes e no plano de criação de um mercado comum, a oportunidade integrar-se às duas economias líderes do subcontinente.

Logo após a quebra dos acordos cobertos pelo Acordo Geral de Tarifas e Comércio (GATT), no contexto do regionalismo aberto e das políticas neoliberais da década de 1990, o MERCOSUL surge com uma pretensão econômico-comercial, indicando metas ousadas em curto prazo na tentativa de reproduzir a experiência europeia. 0 marco de criação do bloco foi a assinatura do Tratado de Assunção m 1991, a partir do qual os membros efetivos do bloco são denominados Estados Partes.

Diferente da atualidade em que cada vez são mais comuns as iniciativas bilaterais, na década de 1990, a formação de blocos econômicos era a alternativa para garantir maior competitividade no mercado internacional (CHESNAIS, 1996, p. 32). No âmbito regional, após a criação do MERCOSUL houve um aumento do comércio regional que passou de 4,5 bilhões em 1980 para 8,1 bilhões em 1992 (SECRETARIA DA ALADI, 2015).

Embora o dinamismo comercial tenha trazido vantagens para os Estados Partes, os ganhos permaneceram maiores para os membros de maior peso econômico e político, denominados membros maiores (Argentina e Brasil) (OLIVEIRA CRUZ, 2019, p. 34). Em contraposição, aos membros menores (Paraguai e Uruguai) restou um descontentamento crescente em relação às assimetrias existentes no MERCOSUL.

As assimetrias no MERCOSUL demonstram-se a partir das diferenças no Produto Interno Bruto (PIB) dos Estados Partes, na dimensão territorial e no contingente populacional. Logo, as possibilidades de produção; disponibilidade e qualificação da força de trabaIho; tamanho do mercado consumidor; e as condições de circulação, concentração e reprodução de capital são distintas. Esses aspectos incidem na organização espacial em diferentes âmbitos da escala regional (subcontinental, nacional, mesorregional e entre cidades), diferenciando espaços luminosos e opacos.

$\mathrm{Na}$ tentativa de colaborar para a diminuição das assimetrias no bloco, em 2004 foi criado o Fundo para a Convergência Estrutural do MERCOSUL (FOCEM). O objetivo deste artigo é discutir o papel do fundo no financiamento de projetos de infraestruturas, suas potencialidades e limites.

Para tanto, este artigo está dividido em duas partes. A primeira parte "O FOCEM", inclui os aspectos gerais sobre a criação, organização e recursos do fundo, a partir da análise de dados e decretos que ajudam a compreender a contribuição e a complexidade do mesmo ao longo dos quinze anos de funcionamento. A segunda parte, "Análise regional do FOCEM: uma questão complexa" propõe uma discussão sobre as desigualdades e assimetrias na escala regional como resultado do processo de acumulação e desenvolvimento capitalista, indicando alguns aspectos que devem ser aprimorados no FOCEM.

A metodologia utilizada para a elaboração do artigo incluiu uma revisão bibliográfica sobre a criação e os rebatimentos do FOCEM no MERCOSUL, a fim de discutir à luz das dinâmicas espaciais contemporâneas o papel do fundo de convergência. Além disso, houve o levantamento e análise de dados quantitativos relacionados ao PIB dos Estados Partes do MERCOSUL e do percentual de contribuição, distribuição de recursos e utilização de financiamento dos Estados Partes originados do FOCEM, a partir dos quais foi possível visualizar o descompasso econômicos e as assimetrias regionais.

\section{O FOCEM}

A promoção da integração regional requer a criação de aparatos institucionais que apoiem com eficácia este processo. Fundos estruturais são estratégias que visam diminuir as assimetrias existentes entre os membros de um acordo/bloco econômico.

Além de ser um obstáculo para o aprofundamento da integração, as assimetrias geram descontentamento dos Estados nacionais que fazem parte do acordo e que não possuem condições para arcar com os custos necessários, podendo resultar, inclusive, em instabilidades político-institucionais (TESSARI, 2012, p. 115).

Conforme mencionado na introdução, as assimetrias podem ser identificadas, dentre outras coisas, pelos descompassos econômicos. Ao observar o Produto Interno Bruto (PIB) dos Estados Partes do MERCOSUL (membros efetivos), é possível perceber 
que a capacidade de recursos disponibilizados para o fomento da rede de infraestruturas, ampliação da capacidade produtiva e do comércio internacional, bem como para a promoção da integração regional tende

Gráfico 1: Produto Interno Bruto (PIB) dos Estados Partes do MERCOSUL no período de 1980 a 2017

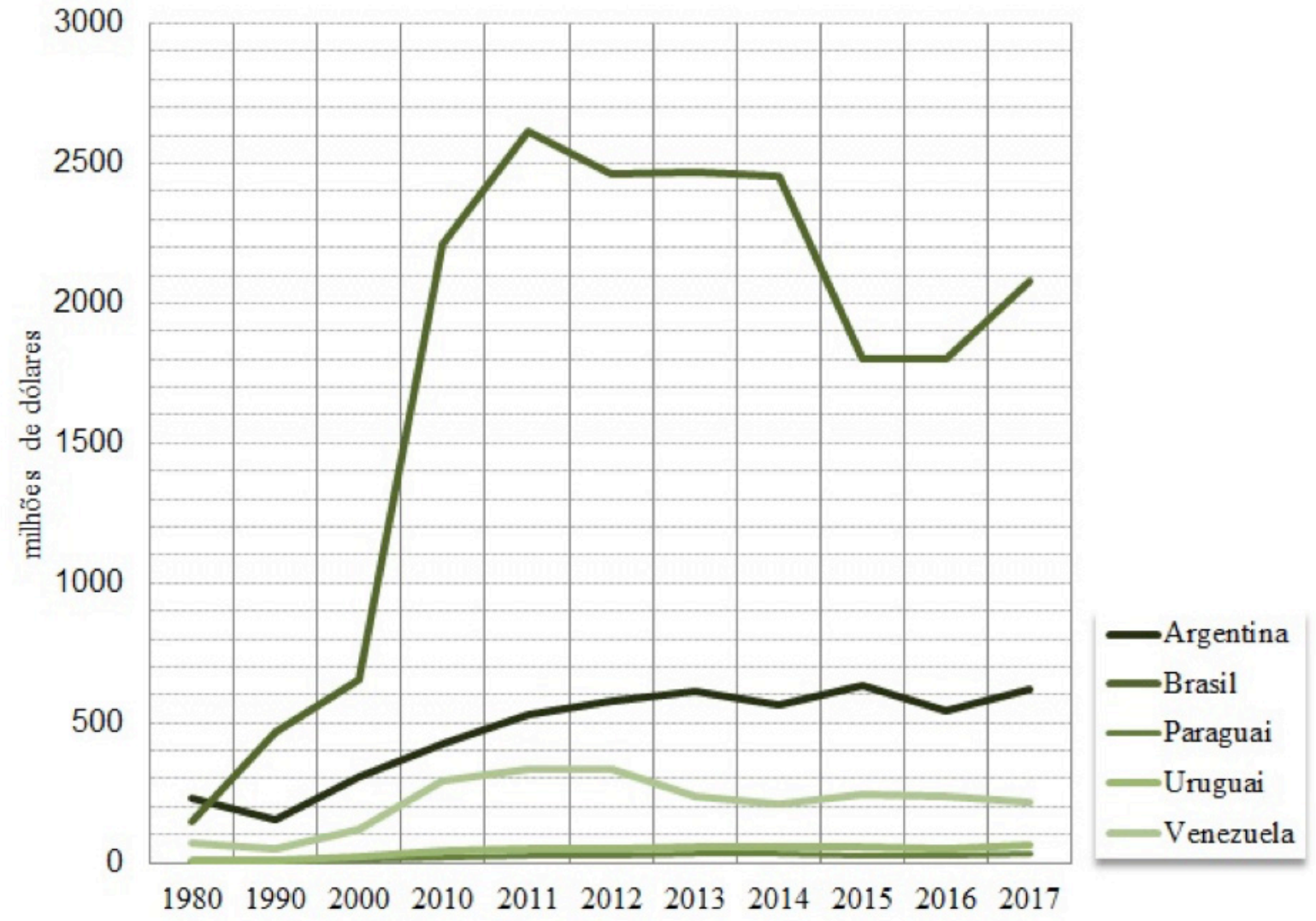

Fonte dos dados: ALADI, 2018

Elaboração: Autora, 2019

a ser desigual, diante dos descompassos existentes.

O Gráfico 01 mostra a evolução do Produto Interno Bruto (PIB) dos Estados Partes do MERCOSUL no período de 1980 a 2017. Nota-se a diferença do PIB dos países membros do bloco, ampliada a partir dos anos 2000, sobretudo, em função do crescimento da economia brasileira.

Considerando o descompasso das economias mercosulinas e a necessidade de combate às assimetrias, visando o aprofundamento do processo de integração regional, os Estados Partes, iniciaram em 2003, o debate sobre a criação de um fundo estrutural para o bloco (TESSARI, 2012, p. 122). No ano seguinte (2004), o FOCEM foi criado pelo Conselho do Mercado Comum (CMC) e entrou em funcionamento no ano de 2007, contemplando os seguintes programas:

1. Convergência estrutural (que inclui a diminuição das economias e regiões no bloco, sendo foco a melhoria dos sistemas de comunicação e a integração fronteiriça);

2. Desenvolvimento da competitividade (especialmente nos setores de ciência, tecnologia e integração produtiva, que facilitem o comércio intra-bloco a partir de uma nova organização produtiva e trabalhista);

3. Coesão social (com ênfase nas zonas fronteiriças e que contemplam projetos de saúde, educação, redução da pobreza e desemprego);

4.Fortalecimento

da

estrutura institucional e do processo de integração.

A série histórica do Produto Interno Bruto (PIB) dos 
Estados Partes serviu como referência para o cálculo-base que definiu a porcentagem anual de contribuição não-reembolsável para o FOCEM, assim como para a utilização dos recursos. Logo, originalmente foi estabelecido que o Brasil e Argentina (membros do MERCOSUL) contribuíssem com o maior montante: $70 \%$ e $27 \%$, respectivamente. O Uruguai com $2 \%$ e o Paraguai com $1 \%$ do total de cem milhões de dólares. O percentual passou a ser praticado apenas no terceiro ano após a criação do fundo, já que nos primeiros dois anos, os Estados Partes contribuíram com $50 \%$ e $75 \%$ do percentual total estabelecido para a execução de projetos-piloto (FOCEM, 2005).

Com a entrada da Venezuela no MERCOSUL em 2012, o país passou a contribuir com vinte e sete milhões de dólares por ano, cuja disponibilidade de recursos para o financiamento de projetos foi estipulada em quinze milhões e meio de dólares (MERCOSUL, 2015). Assim,

Gráfico 2: Contribuição dos Estados Partes ao FOCEM a partir de 2015.

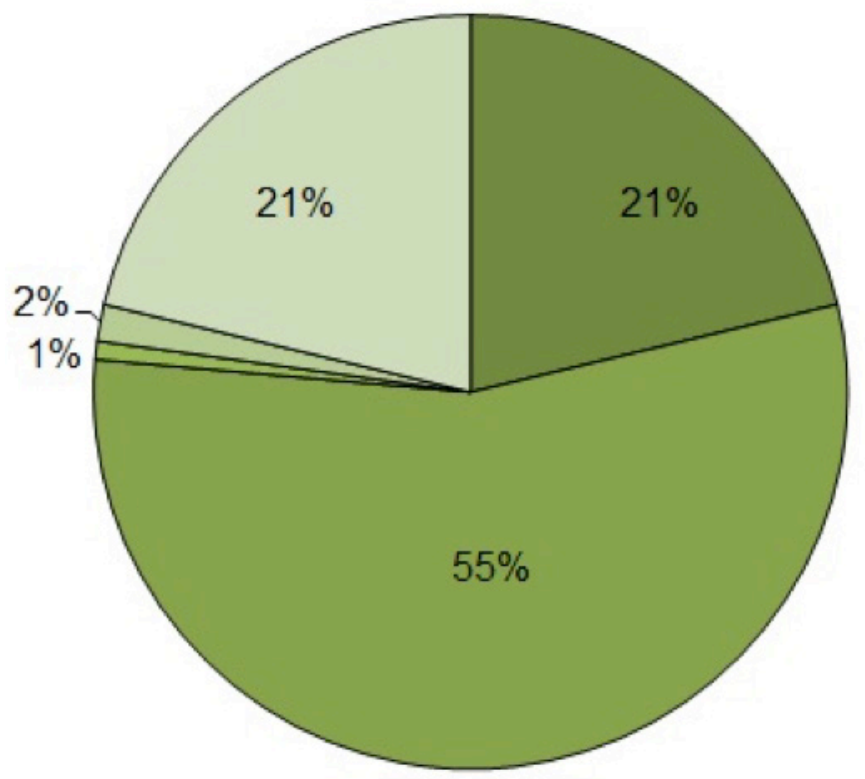

\section{$\square$ Argentina 口Brasil $\square$ Paraguai 口Uruguai $\square$ Venezuela}

Fonte dos dados: FOCEM, 2015

Elaboração: Autora, 2019

o fundo que até 2012 contava com a contribuição de cem milhões de dólares anuais, passou a ser composto por cento e vinte e sete milhões de dólares em 2015 (no terceiro ano da adesão da Venezuela ao bloco), cuja contribuição passou a ser conforme mostra o gráfico 02.

Se a contribuição anual com o FOCEM foi estipulada pela série histórica do PIB dos países, no qual os membros maiores do MERCOSUL contribuem com a maior porcentagem do fundo, a disponibilização de recursos segue a mesma proporção. Os membros menores que possuem a menor média da série histórica do PIB são os que têm à disposição o maior montante de recursos disponíveis, sendo $48 \%$ para o Paraguai e $32 \%$ para o Uruguai (já o Brasil e a Argentina têm 10\% cada).

A partir de 2015, com as alterações na porcentagem de contribuição estabelecida aos Estados Partes (gráfico 02), os recursos disponíveis para o financiamento de projetos também foram alterados, conforme mostra o gráfico 03 .

0 gráfico 04 mostra os recursos disponíveis para o financiamento de projetos do FOCEM, segundo os Estados Partes do MERCOSUL no período de 2008 a 2019. Os valores não utilizados em anos anteriores são cumulativos, por isso anualmente o total de recursos disponíveis ultrapassa o valor anual de contribuição de cento e vinte e sete milhões de dólares. Além disso, o FOCEM admite contribuições voluntárias dos Estados Partes ou de terceiros, instituições ou organismos internacionais, que podem ser destinadas especificamente para um projeto em curso, como por exemplo, a contribuição brasileira de trezentos milhões de dólares ocorri- 
Gráfico 3: Recursos disponibilizados aos Estados Partes para o financiamento de projetos pelo FOCEM a partir de 2015.

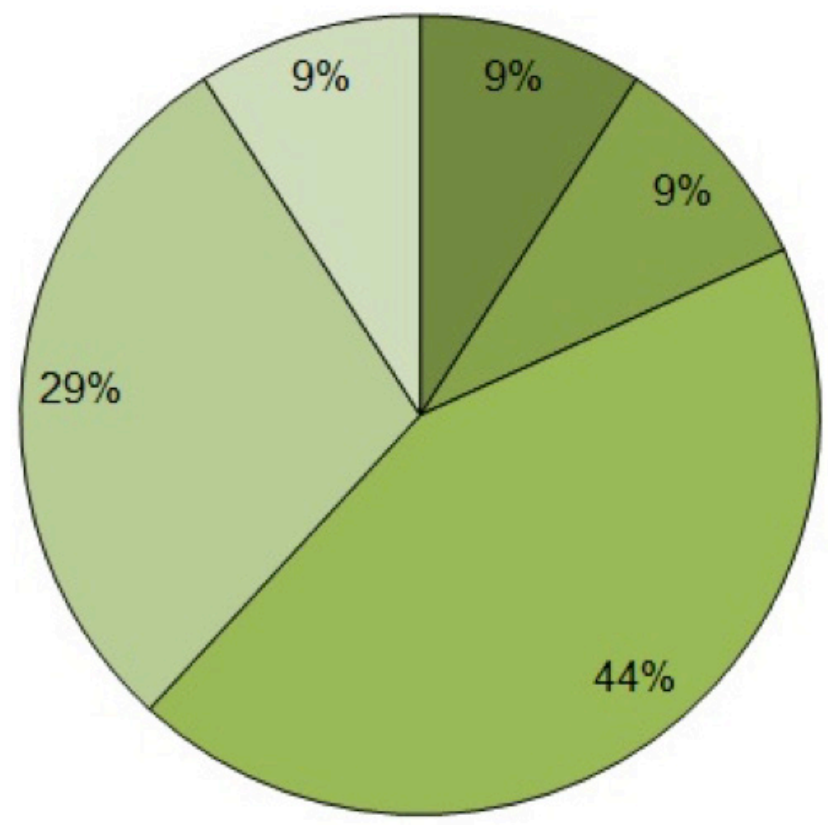

$\square$ Argentina

$\square$ Brasil

$\square$ Paraguai

$\square$ Uruguai

$\square$ Venezuela

Fonte dos dados: FOCEM, 2015

Elaboração: Autora, 2019

da em 2010 para o projeto paraguaio "Construção da Linha de Transmissão 500 Kv Itaipú - Villa Hayes, da
Subestação Villa Hayes e da ampliação da Subestação Margem Direita Itaipu" (DESIDERÁ NETO, 2015, p.238).

Gráfico 4: Distribuição dos recursos do FOCEM no período de 2008 a 2019

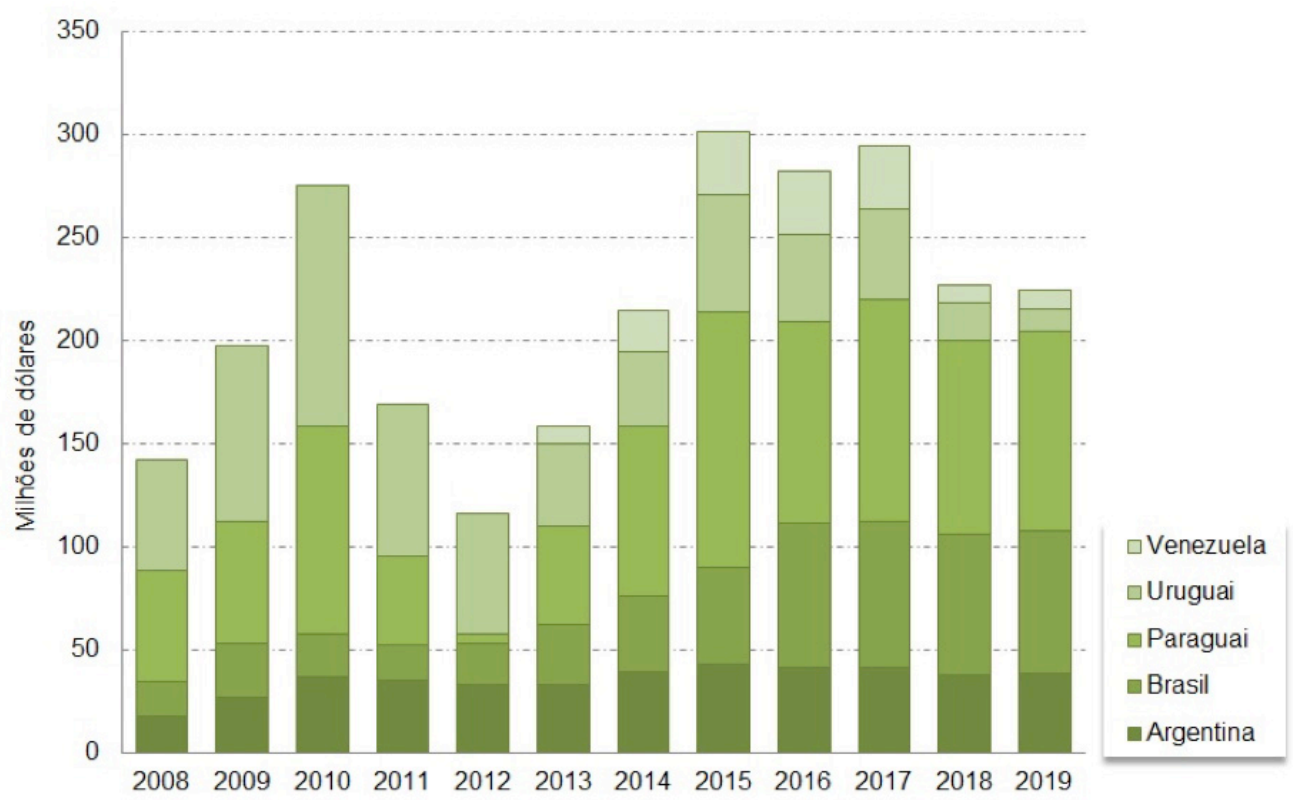


Nota-se que no Gráfico 04 que o maior montante de recursos disponíveis é destinado aos membros menores. O Paraguai teve uma diminuição dos recursos disponíveis para o financiamento de projetos no país no ano de 2012, por conta da quebra do Protocolo de Ushuaia com o impeachment do ex-presidente Fernando Lugo. Conforme estabelece o protocolo, os países que desrespeitarem o acordo democrático devem ser punidos com a suspensão de sua participação nos órgãos do MERCOSUL, o que inclui o FOCEM. A mesma punição tem sido aplicada à Venezuela nos anos de 2018 e 2019, dada à crise política e econômica que o país enfrenta.

Existe uma diferença de tipos de projetos financiados 1 com recursos do FOCEM entre os membros do MERCOSUL. Os membros menores utilizam majoritariamente (acima de 70\%) os recursos disponíveis para o financiamento de projetos de infraestrutura, ao contrário dos membros maiores (OLIVEIRA CRUZ, 2019, p.42). Esse fato é decorrente do alto custo para a execução de projetos de infraestruturas (transportes e energia). Além disso, eles estão diretamente ligados ao fomento das cadeias produtivas, sendo elementos fundamentais na produção e circulação de mercadorias.

É fundamental ressaltar que os projetos de infraestruturas fazem parte do Programa 1. Convergência estrutural (citado anteriormente), que é o principal foco de financiamento de projetos. Nos primeiro quatro anos do FOCEM, os recursos financeiros foram prioritariamente destinados para esse programa (FOCEM, 2005), justamente por conta da dificuldade no fomento à rede de transportes e energia - obstáculos para a integração produtiva no MERCOSUL. Rede cuja característica é desigual, cuja sobreposição está concentrada em torno dos principais polos de produção de mercadorias e concentração de capitais.

Por outro lado, o total de contribuição de cento e vinte e sete milhões de dólares anuais não é suficiente para projetos de grandes dimensões na rede de transportes e energia dos países. Para Tessari (2012, p.133), a explicação pelo baixo orçamento é por conta da tentativa em conciliar a necessidade de compensação financeira para os membros menores e ao mesmo tempo não gerar um grande ônus financeiro para os membros maiores.

Diante deste contexto, o regulamento do FOCEM foi adequado com a assinatura do Decreto $n^{\circ} 04 / 18$, em junho de 2018. A decisão foi justificada no decreto pela necessidade de aumentar a efetividade do fundo e fortalecer a gestão institucional do FOCEM. Neste decre-

${ }^{1}$ Antes da liberação do montante para o financiamento de um projeto, eles precisam ser submetidos pelos Estados Partes ao Conselho de Administração do FOCEM (CRFOCEM) do qual faz parte a Unidade Técnica FOCEM (UTF) - que decide a elegibilidade e o percentual do fundo destinado para o financiamento. to, a necessidade de busca pela complementaridade para o desenvolvimento de programas e projetos, visando assistência técnica e complementação financeira foi um dos principais pontos considerados para a assinatura do "Acordo-Quadro entre o Mercado Comum do Sul (MERCOSUL) e o Fundo Financeiro para o Desenvolvimento da Bacia do Prata (FONPLATA). Com a adequação do regulamento do FOCEM, foi estabelecido que: A origem da contribuição com o fundo poderá ser de recursos de contas remuneradas no FOCEM e de acordos de administração financeira.

Os Estados Partes deverão designar instituições financeiras para o depósito de suas contribuições, sendo que as instituições não terão responsabilidade sobre as transferências dos recursos que deverão ser feitas em dólar.

Os recursos passam a ser administrados pelo coordenador-executivo do FOCEM. Ele é responsável por escoIher as contas bancárias do fundo, considerando as meIhores condições operacionais e de remuneração. Há a possibilidade de firmar acordos de administração financeira com outros organismos regionais de financiamento para o desenvolvimento, como é o caso do FONPLATA.

O fundo terá uma reserva de contingência equivalente a $10 \%$ dos desembolsos feitos anualmente para que não haja eventual interrupção na execução de projetos em andamento.

Segundo o artigo $6^{\circ}$, a previsão é que as decisões sejam incorporadas aos ordenamentos jurídicos dos Estados Partes do MERCOSUL antes de 11 de junho de 2019.

$A$ adequação do regulamento do FOCEM demonstra a necessidade de ampliar as possibilidades do fundo, associando-se a um dos principais fundos financeiros que atuam no financiamento de projetos de infraestruturas na América do Sul, que é o FONPLATA, haja vista a atuação deste em outros acordos regionais como, por exemplo, o Conselho Sul-americano e Infraestrutura e Planejamento (COSIPLAN/IIRSA).

Outro ponto fundamental a ser observado é a relevância do FOCEM para o MERCOSUL diante da prorrogação do funcionamento do fundo pelo Decreto $n^{\circ}$ 22/15. Quando os Estados Partes firmaram o acordo para a criação do FOCEM, a expectativa era que a atuação do fundo durasse dez anos. Em 2015, o prazo foi prorrogado por mais dez anos (até 01 de janeiro de 2026).

\section{Análise regional do FOCEM: uma questão complexa}

Do ponto de vista político, de acordo com Desiderá Neto (2015, p. 219), os debates acerca das assime- 
trias no MERCOSUL e sobre o aumento da cooperação e desenvolvimento ganharam destaque a partir das eleições dos governos de Néstor Kirchner, na Argentina, e de Luiz Inácio Lula da Silva, no Brasil. Neste contexto, o FOCEM foi o resultado da ampliação das pautas de discussão para o aprofundamento da integração regional.

Neste sentido, Tessari $(2012$, p. 122) destaca o discurso do ex-presidente Luiz Inácio Lula da Silva durante a reunião de Presidentes do MERCOSUL, realizada na cidade de Córdoba no ano de 2016. Naquela ocasião, o ex-presidente brasileiro disse o seguinte:

\begin{abstract}
O Mercosul tem diante de si o desafio de reinventar-se e atender às expectativas de todos os seus membros. Temos de desenhar mecanismos que equacionem em definitivo as assimetrias, inclusive com o aporte de novos recursos. Precisamos encarar de frente as questões relativas ao fortalecimento institucional e à implementação, em cada um de nossos países, das decisões e acordos que tomamos no bloco (SILVA, 2006, s/p apud TESSARI, 2012, p. 122 e 123).
\end{abstract}

Além das assimetrias entre Estados Partes, as regiões menos desenvolvidas também são citadas como foco para o financiamento de projetos de infraestruturas no Decreto $n^{\circ} 18 / 05$ que trata sobre a integração e o funcionamento do FOCEM.

As assimetrias e desigualdades regionais são contradições inerentes ao processo de acumulação e desenvolvimento capitalista, aliadas às heranças regionais e sub-regionais de ocupação territorial, exploração dos recursos e abertura ao capital estrangeiro. Ou seja, a organização espacial de uma determinada região está diretamente ligada à atuação dos agentes detentores do capital (grandes empresas, bancos, corporações) e às escolhas feitas pelo Estado capitalista, permitindo com que a lógica de acumulação desigual se perpetue como base para a reprodução do capital e das relações sociais (CORRÊA, 2000, p. 33).

As contradições regionais sul-americanas foram acentuadas com a abertura econômica para o capital internacional e atuação de empresas multinacionais, cuja expressividade tornou-se mais evidente a partir da década de 1970, aprofundadas com as políticas neoliberais de 1990 (contexto de criação do MERCOSUL). Neste mesmo período, os membros maiores do MERCOSUL vivenciaram as transformações decorrentes do meio técnico-científico-internacional, discutido por Santos (2008, p. 159).

A industrialização tardia no subcontinente e as transformações da economia em global, informacional e organizada em rede (CASTELLS, 1999, p. 189) propiciaram a ampliação das desigualdades. As desigualdades atingiram profundamente todas as escalas geográficas (do subcontinente à cidade). 0 resultado foi a reconfiguração da hierarquia entre os lugares graças ao avanço da globalização e as novas lógicas de divisão territorial do trabalho, que tornaram o espaço cada vez mais reticulado.

A coexistência da sobreposição e escassez das redes, acompanhadas pela multiplicidade e fluidez crescente dos fluxos, tornam dispensáveis os lugares sem os requisitos necessários para atender as exigências dessa nova relação dialética entre fixos e fluxos. Dessa forma, eles permaneceram à margem das interações promovidas entre o movimento e a materialidade espacial, caracterizados como espaços opacos.

Milton Santos e Maria Laura Silveira (2006, p. 264) utilizam os termos espaços luminosos e espaços opacos para demonstrar as diferenças entre os lugares quanto à acumulação de capital, o potencial de atração de fluxos, e a consequente competitividade entre os lugares no contexto do meio técnico-científico-informacional.

Chamamos de espaços luminosos aqueles que mais acumulam densidades técnicas e informacionais, ficando assim mais aptos a atrair atividades com maior conteúdo de capital, tecnologia e organização. Por oposição, os subespaços onde tais características estão ausentes seriam os espaços opacos. Entre esses extremos haveria toda uma gama de situações. Os espaços luminosos, pela sua consistência técnica e política, seriam os mais suscetíveis de participar de regularidades e de uma lógica obediente aos interesses das maiores empresas (SANTOS e SILVEIRA, 2006, p. 264).

0 desequilíbrio entre espaços luminosos e espaços opacos dificulta o aprofundamento do processo de integração regional e a expansão da competitividade do MERCOSUL no cenário internacional, principalmente, por conta dos gargalos infraestruturais existentes nos espaços opacos.

0 investimento em infraestruturas é uma tentativa de estímulo à atração de capitais que ao torna mais dinâmica a relação entre fixos e fluxos. Entretanto, a falta de recursos para o investimento nos países periféricos é um entrave para o fomento da rede de transportes e energia. Sem a expansão do conteúdo técnico adequado às redes existentes, o custo para a produção e circulação de mercadorias aumenta, diminuindo o potencial de competitividade.

Opadrão de ocupação sul-americano ea concentração dos núcleos urbanos no litoral do subcontinente resultaram em uma herança histórica de concentração do contingente populacional regional. A interiorização da rede de infraestruturas tornou-se um desafio, tanto do ponto de vista das características físicas do território, como pela ausência de recursos suficientes para promovê-la.

0 desafio afeta a todos os países sul-americanos, no entanto, no recorte territorial mercosulino, ele 
é maior para os membros menores do bloco. As assimetrias e desigualdades econômicas explicam as diferenças no montante disponível por cada país para o investimento em infraestruturas. Tal desafio torna-se ainda maior com o objetivo de atingir a integração regional, pois ela depende diretamente da fluidez do espaço reticulado e de seu incremento técnico.

A questão regional no MERCOSUL é complexa, pois ela não está limitada às diferenças estabelecidas entre os limites nacionais dos Estados Partes. Cada território nacional possui pontos opacos que demandam investimento na rede de transportes e energia. Ou seja, mesmo nos membros maiores, as desigualdades regionais provenientes do processo de acumulação capitalista impõem-se à integração regional, como é o caso das mesorregiões nordeste e norte do Brasil. A circulação de mercadorias e as possibilidades de integração produtiva nesses espaços são reduzidas.

Por outro lado, com o estímulo e atração de capitais destinados aos espaços luminosos, esses tendem a receber maior estímulo à ampliação de suas infraestruturas para dar conta de atender os fluxos internacionais. 0 caso do Paraguai é ilustrativo. Para Vázquez (2006, p. 56), o MERCOSUL reforçou a tendência de ocupação nas zonas leste e sul da região Oriental do país, que concentra a produção de soja e atrai empresários estrangeiros (brasileiros, principalmente). 0 resultado foi a marginalização de áreas menos desenvolvidas, como o Chaco paraguaio, cuja localização está distante da zona fronteiriça com Argentina e Brasil.

Santos (2008, p. 228) atribui à configuração da organização espacial das regiões no âmbito nacional não somente o cenário econômico, mas também às decisões políticas. Para ele, os mecanismos de poder ditam as escolhas de envelhecimento ou modernização dos lugares via orçamento para a execução de um plano ou pela legislação.

No contexto do MERCOSUL esse fato é evidente pelo perfil dos projetos submetidos ao CRFOCEM, majoritariamente do setor de infraestruturas. 0 perfil dos projetos está diretamente relacionado aos agentes privilegiados pelo conteúdo técnico na circulação das mercadorias, na tentativa de integração produtiva, no potencial de novos negócios, napossibilidade demaximização dos lucrosetc.

\section{Considerações finais}

Com as transformações no cenário político e econômico (a partir do ano de 2003) e o resultado do debate sobre a necessidade de combate das assimetrias no MERCOSUL, diferente do contexto de minimização do pa- pel dos Estados nacionais em que o MERCOSUL foi criado, o FOCEM trouxe uma nova perspectiva para o bloco.

A nova perspectiva direcionou-se à democratização do bloco, uma alternativa para a compensação dos descompassos econômicos e vantagens adquiridas com o processo de integração. Entretanto, um aspecto problemático é o montante anual de composição do fundo, aquém das necessidades de financiamento para as infraestruturas. Diante disso, deve ser considerada a possibilidade de adesão de novos membros com condições análogas aos membros menores no MERCOSUL (como é o caso da Bolívia que está em processo de adesão desde 2012), demandando uma redistribuição dos recursos disponíveis sem contar com um grande impacto na composição do fundo.

Outro ponto a ser considerado é a escala prioritária para financiamento dos projetos. Obviamente, os membros menores são os que mais necessitam de fomento às infraestruturas, porém existem regiões localizadas nos países líderes do MERCOSUL (Brasil e Argentina) que carecem deste tipo de financiamento, como é o caso do interior do nordeste brasileiro.

Logo, observando a complexidade regional do MERCOSUL e as particularidades de cada país, conclui-se que apesar da contribuição do FOCEM para a integração regional no bloco, a escassez de recursos disponíveis e os critérios territoriais para a seleção dos projetos necessitam ser debatidos e aprimorados. É fundamento observar as dinâmicas internas de cada país para indicar a aplicação dos recursos em projetos que abrangem os espaços opacos (sobretudo nos membros maiores).

Tal aprimoramento demanda o fortalecimento da estrutura institucional do bloco. Porém, diante dos novos rumos da integração regional sul-americana e particularmente do MERCOSUL, a partir do ano de $2016 \mathrm{com}$ a defesa da flexibilização do bloco e a tendência mundial crescente de acordos binacionais, cabe uma continuidade do processo de reflexão e questionamento sobre o papel do FOCEM no MERCOSUL. Portanto, o debate não se esgota neste artigo, por isso, a preocupação foi indicar caminhos para a investigação de trabalhos futuros, diante do cenário econômico e político de incertezas, no qual a diminuição das assimetrias não possui protagonismo nas discussões sobre a integração regional. Ao contrário, com a ênfase no estabelecimento de acordos bilaterais com outros países fora da região, o debate sobre as assimetrias tende ao enfraquecimento paulatino. 


\section{Referências}

ALADI. Indicadores socioeconômicos - PIB. 2018. Disponível em: http://www.aladi.org/sitioaladi/indicadoresSocioeconomicosP.html, acesso em 20/02/2019.

CASTELLS, Manuel. A sociedade em rede. São Paulo: Paz e Terra, 1999.

CHESNAIS, François. A Mundialização do Capital. Tradução Silvana Finzi Foá, São Paulo, Xamã, 1996.

CORRÊA, R. L. Região e organização espacial. São Paulo: Editora Ática, 2000.

DESIDERÁ NETO, W. A. O Brasil, a América do sul e a cooperação Sul-Sul. In: RAMANZINI JÚNIOR, H; AYEBE, L. F. (orgs). Política externa brasileira, cooperação sul-sul e negociações internacionais. 1. ed. São Paulo: Cultura acadêmica, 2015, p. 211-249.

FOCEM. Integração e funcionamento do fundo para a Convergência Estrutural e Fortaleciment da Estrutura Institucional do MERCOSUL. MERCOSUL/CMC/DEC. No 18/05. 2005. Disponível em: https://focem.mercosur.int/uploads/ normativa/DEC_018-2005_PT_FERR_IntegFuncFOCEM-2.pdf, acesso em 19/02/2019

Continuidade do funcionamento do Fundo para a Convergência Estrutural do MERCOSUL. MERCOSUL/CMC/ DEC. No 22/15. 2015. Disponível em:N https://focem.mercosur.int/uploads/normativa/DEC_022-2015_PT_Renovacao\%20FOCEM-4.pdf, acesso em 15/02/2019.

Adequação do regulamento do fundo para a convergência estrutural do MERCOSUL. MERCOSUL/CMC/DEC. N 04/18. 2018. Disponível em:https://focem.mercosur.int/uploads/normativa/DEC_004-2018_PT_Adec\%20Regulamento\%20FOCEM-0.pdf, acesso em: 19/02/2019.

Normas institucionais. 2019. Disponível em: https://focem.mercosur.int/pt/normas/?tipo=normativa-institucional, acesso em 10/02/2019.

MELLO, L. I. A. A geopolítica do Brasil e a Bacia do Prata. 1987. Dissertação (Mestrado em Ciências Políticas). Departamento de Ciências Sociais, Universidade Católica de São Paulo.

MERCOSUL. Saiba mais sobre o MERCOSUL. 2019. Disponível em: http://www.mercosul.gov.br/saiba-mais-sobre-o-mercosul, acesso em 01/02/2019.

OLIVEIRA, M. O. A integração bilateral Brasil-Argentina: tecnologia nuclear e MERCOSUL. Revista Brasileira de Política Internacional. vol.41. n.1. Jan./Jun 1998.p. 5-23. Disponível em: http://www.scielo.br/scielo.php?script=sci_arttext\&pid=S0034-73291998000100001, acesso em 24/02/2017.

OLIVEIRA CRUZ, D. A. M. O papel do Brasil no processo de integração regional do MERCOSUL. In: Revista formação (Online). Vol. 25. n. 26. p. 27-46. Disponível em: http://revista.fct.unesp.br/index.php/formacao/article/view/5506/4701, acesso em 20/02/2019.

SANTOS, M. A natureza do espaço: Técnica e Tempo, Razão e Emoção. 4. ed. São Paulo: Edusp, 2008.

SANTOS, M; SILVEIRA, M. L. O Brasil: território e sociedade no início do século XXI. 9. ed. São Paulo: Editora Record, 2006.

SECRETARIA DA ALADI. Sistema de informação de comércio exterior. 2015. Disponível em: http://consultawebv2. aladi.org/sicoexV2/jsf/home.seam, acesso em 10/12/2018.

TESSARI, G. R. Regional integration, the structural funds and institutional stability in Mercosur: the creation of FOCEM. Perspectivas, São Paulo, v.42, p.115-137, jul./dez. 2012.

VÁZQUEZ, F. Territorio y población: nuevas dinámicas regionales en el Paraguay. Asunción: ADEPO, 2006. 